\title{
Findings in bone scintigraphy with [99mTc] Tc-MDP of a mandibular ameloblastic carcinoma
}

\author{
Liliana Patricia Torres ${ }^{1}$ (D), Marylin Acuña Hernandez ${ }^{1}$ (D), Tatiana Morales Avellaneda ${ }^{1,2}$, \\ Andrés llich González Ramírez ${ }^{1,2}$ (i) \\ 'Universidad AutóNoma De Bucaramanga, Santander, Colombia \\ ${ }^{2}$ Spect Medicina Nuclear S.A.S, Centro medico carlos ardila Lulle, Bucaramanga, Colombia
}

[Received 6 V 2020; Accepted 6 X 2020]

KEY words: ameloblastic carcinoma, mandible, radionuclide imaging

Nucl Med Rev 2021; 24, 1: 27-28

\section{Introduction}

Ameloblastic carcinoma, a malignant odontogenic tumor that combines the histological characteristics of ameloblastoma with cytological atypia (OMS), is extremely rare and mainly affects men in the mandible and maxillary region (2/3 of cases) without a specific age.

Its etiology is unknown, although most cases are de novo and to a lesser extent develop from residual epithelial tissue to dental development such as ameloblastoma or odontogenic cyst.

The diagnosis is often difficult and is based on histopathological characteristics.

\section{Clinical case}

26-year-old man, in 2016 refers 3 years progressive growth in the right half of face indicating CT of the temporomandibular joint with evidence of odontogenic cyst that compromises the angle, ascending branch, mandibular condyle and right coronoid process of the mandible, drainage was performed.

By 2019 the lesion associated with pain and swallowing limitation reappears (Fig. 1). The CT sean of the temporomandibular joint where a predominantly cystic tumor mass with an over-aggregated lytic process is observed affecting the angle of the right side of the mandible as well as posterior dental structures of the lower jaw. The biopsy reported involvement of ameloblastic carcinoma with associated tumor necrosis.

Bone scintigraphy with SPECT and fusion image with CT scan as extension study is indicated, showing right mandibular lesion

Correspondence to: Marylin Acuña Hernandez

Universidad AutóNoma De Bucaramanga, Ave. El No 23-60, Tms

CañAveral, Tv. El Bosque, 680003 Floridablanca, Santander, Colombia

e-mail: macuna766@unab.edu.co

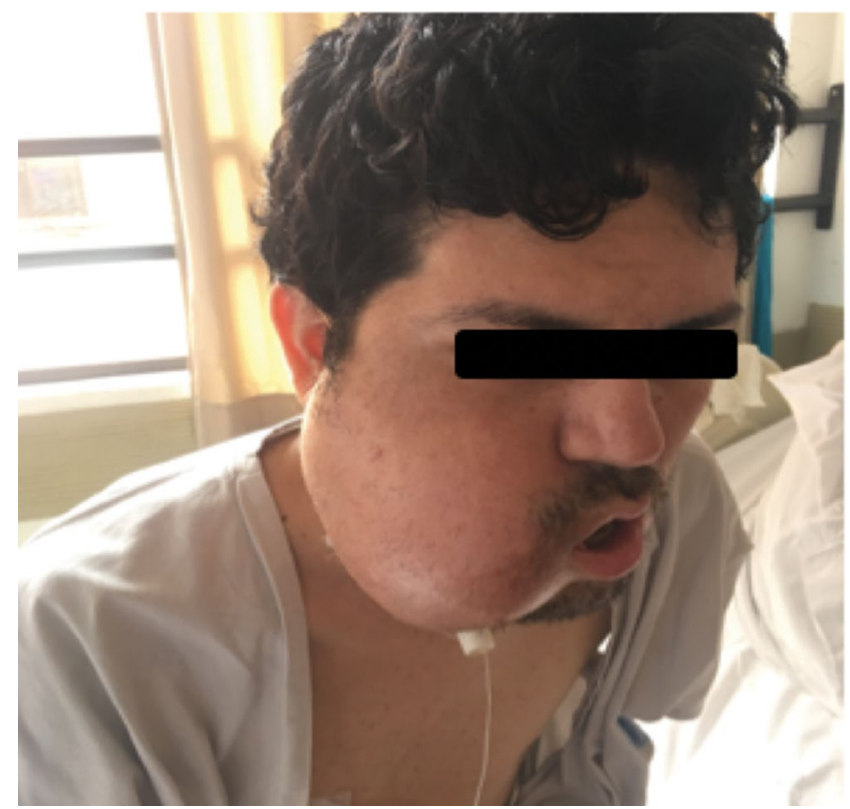

Figure 1. Physical examination of the patient with evidence of a large mass in the right half of the face

with peripheral increase uptake and low-uptake center, with no evidence of metastatic lesions (Figs. 2, 3 and 4).

\section{Discussion}

Ameloblastic carcinomas are usually aggressive entities with significant local involvement, recurrent and metastatic to cervical lymph nodes, lungs, bone, liver and brain [1, 3].

The diagnostic images allow an adequate initial staging prior to surgical treatment, allowing better planning $[3,4]$ 


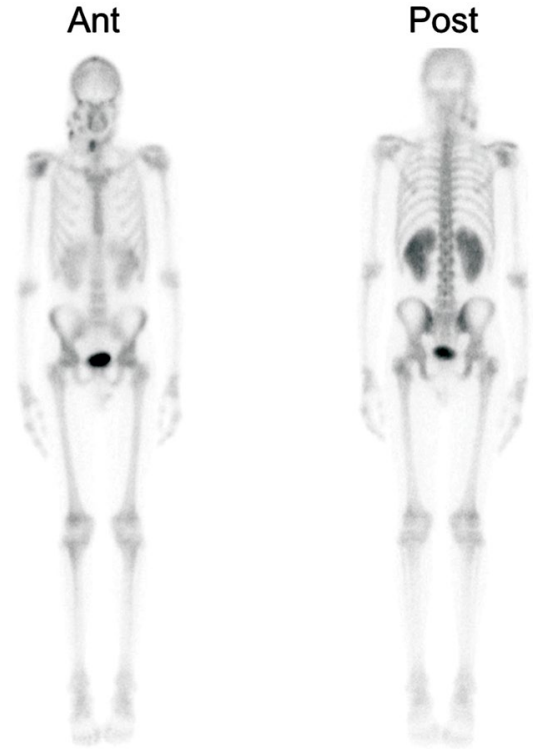

Figure 2. Whole body bone scintigraphy shows an area of peripheral increase uptake and a low-uptake center can be seen in the right mandibular region, also to the right glenohumeral joint has an increase uptake that when interviewing the patient refers to trauma at this level being considered of inflammatory origin

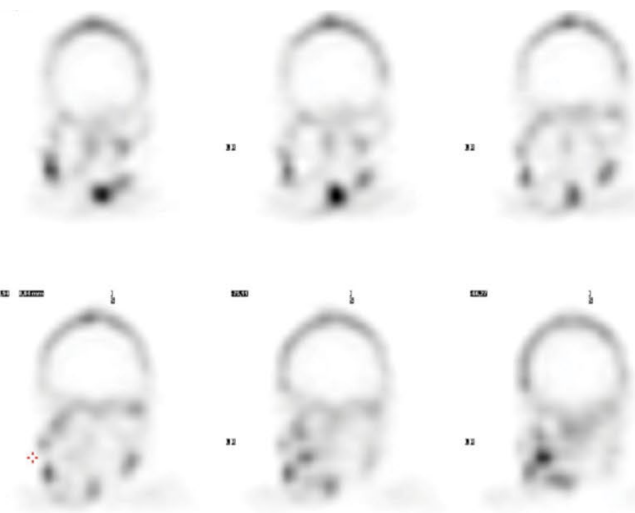

CT or MRI allows to improve locoregional staging with the difficulty of evaluating disease at a distance; for this reason, in recent years have been used the $2-\left[{ }^{18} \mathrm{~F}\right]-\mathrm{FDG}$ PET/CT as a study for initial staging and monitoring, because hypermetabolism is found in the primary lesion and metastatic sites.

Bone scintigraphy with $\left.{ }^{99 \mathrm{~m}} \mathrm{Tc}\right] \mathrm{Tc}-\mathrm{MDP}$ allows the exclusion of metastatic bone lesions, especially when the primary tumor has an early spread. However, it has a limited role in lytic lesions that are reflected as photogenic areas which are associated with osteonecrosis, hypovascularity and aggressive tumor invasion.

\section{References}

1. Braimah R, Uguru C, Ndukwe K. Ameloblastic carcinoma of the jaws: Review of the literature. Journal of Dental and Allied Sciences. 2017; 6(2): 70, doi: 10.4103/jdas.jdas_4_17

2. Pandey S, Bhutia O, Roychoudhury A, et al. Literature review of 86 cases of mandibular ameloblastic carcinoma. Natl J Maxillofac Surg. 2018; 9(1): 2-7, doi: 10.4103/njms.NJMS 33 16, indexed in Pubmed: 29937652.

3. Matsuzaki $\mathrm{H}$, Katase N, Hara M, et al. Ameloblastic carcinoma: a case report with radiological features of computed tomography and magnetic resonance imaging and positron emission tomography. Oral Surg Oral Med Oral Pathol Oral Radiol Endod. 2011; 112(1): e40-e47, doi: 10.1016/j.tripleo.2011.01.023, indexed in Pubmed: 21458329.

4. Bahk YW, Bahk WJ. Malignant Tumors of Bone. Combined Scintigraphic and Radiographic Diagnosis of Bone and Joint Diseases. 2017: 407-450, doi: 10.1007/978-981-10-2759-8 17

Figure 3. Single photon emission computed tomography (SPECT) image of the skull evidenced a lesion described in the right mandibular region

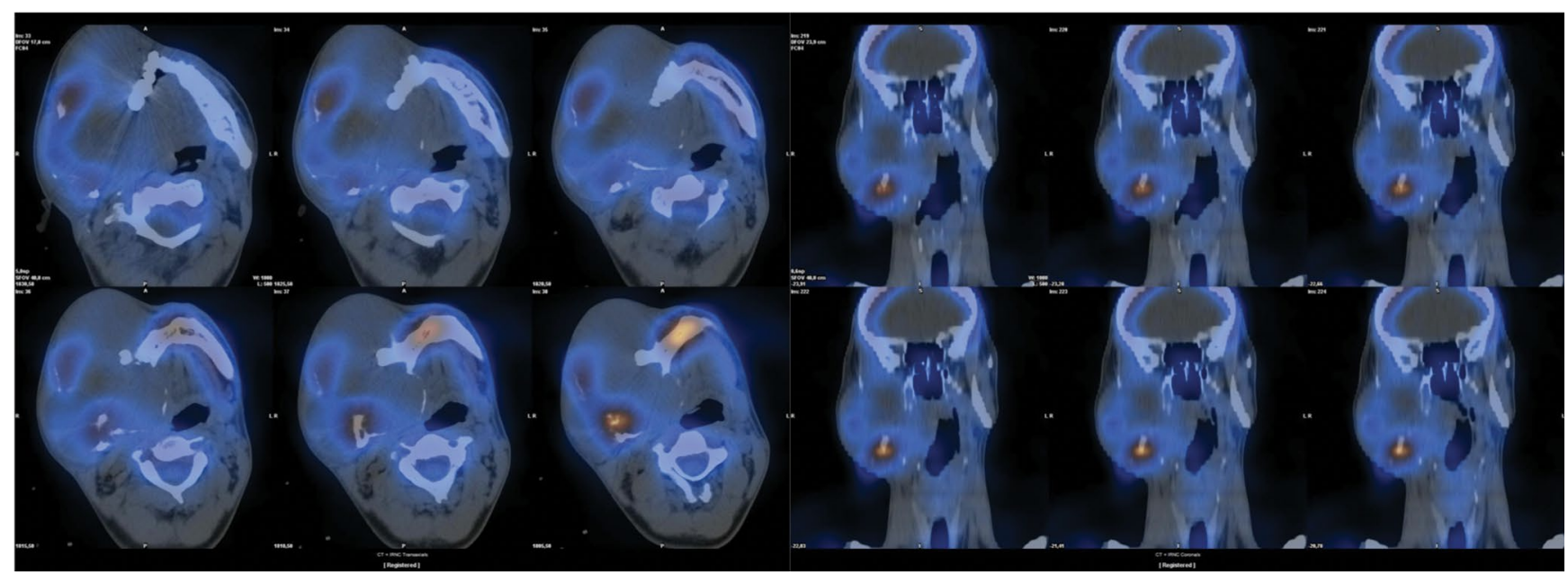

Figure 4. Single photon emission computed tomography (SPECT) image of the skull with CT fusion locating lytic lesion in the right mandible angle with extension to dental structures 